\title{
A MOBILIDADE POPULACIONAL E SUA RELAÇÃO COM O AMBIENTE: BREVE PANORAMA DOS PRINCIPAIS DEBATES*
}

\author{
Carla Craice $^{* *}$
}

\begin{abstract}
Resumo: $O$ artigo realiza um panorama das discussões sobre a mobilidade populacional e sua relação com o ambiente. Para isso, são analisados livros e periódicos organizados pelo Grupo de Trabalho População, Espaço e Ambiente da Associação Brasileira de Estudos Populacionais desde sua primeira publicação em 1993. O conceito de mobilidade adotado nesta investigação compreende o movimento de um grupo populacional pelo espaço, não se restringindo a limites políticoadministrativos e sem fixação de intervalo de tempo. Dentre o conjunto de estudos analisados, a mobilidade esteve presente principalmente em debates sobre cidades, Amazônia e mudanças climáticas. Observou-se que a mobilidade populacional foi tratada a partir de uma relação dialética com a questão ambiental, nem simplesmente causa ou consequência, mas sim estabelecendo laços complexos com o seu entorno.

Palavras-chave: Mobilidade populacional. População. Ambiente.
\end{abstract}

Population mobility and its relation to the environment: a brief overview of the main debates

Abstract: The article presents an overview of the discussions about population mobility and its relation to the environment. For this, we analyze books and journals organized by the Working Group Population, Space and Environment of the Brazilian Association of Population Studies since its first publication in 1993. The mobility concept adopted in this research comprises the movement of a population group through space, not restricted to political and administrative boundaries and with no time interval setting. In the group of analyzed studies, mobility was presented mainly in debates on cities, Amazon and climate change. It was observed that the population

\footnotetext{
* Agradeço ao diálogo junto aos colegas da linha de pesquisa em População, Ambiente, Espaço e Sustentabilidade do Núcleo de Estudos de População "Elza Berquó" (NEPO/Unicamp), essencial para a reflexão aqui presente.

* Instituto de Filosofia e Ciências Humanas, Universidade Estadual de Campinas - Unicamp, Campinas-SP, Brasil (carla.craice@gmail.com). Recebido em: 02/05/2015 - Aceito em: 04/08/2015.
} 
| 64 |

A mobilidade populacional...

mobility was treated from a dialectical relationship with the environmental issues, not just cause or consequence, but establishing complex ties with its surroundings.

Keywords: Population mobility. Population. Environment.

La movilidad de la población y su relación con el ambiente: breve panorama de los principales debates

Resumen: El artículo presenta un resumen de las discusiones sobre la movilidad de la población y su relación con el medio ambiente. Con este fin, analizamos los libros y revistas organizadas por el Grupo de Trabajo de Población, Espacio y Medio Ambiente de la Asociación Brasileña de Estudios de Población desde su primera publicación en 1993. El concepto de movilidad adoptado en esta investigación comprende el movimiento de un grupo poblacional a través del espacio, no restringido a los límites políticos y administrativos y sin ajuste de intervalo de tiempo. En el grupo de los estudios analizados, la movilidad se presentó principalmente en los debates sobre las ciudades, Amazonía y cambios climáticos. Se observó que la movilidad de la población fue tratada como una relación dialéctica con el tema ambiental, no sólo causa o consecuencia, pero estableciendo vínculos complejos con su entorno.

Palabras clave: Movilidad de la población. Población. Ambiente.

\section{Introdução}

Por que os indivíduos se movem pelo território? A proposta da presente investigação é refletir sobre como o ambiente interage com a mobilidade da população. Segundo Leff (2012) o ambiente deve ser tomado enquanto conjunto de relações complexas entre processos de ordem física, biológica e social. $\mathrm{O}$ ambiente não pertence estritamente à ordem da natureza, nem se trata somente de uma construção social, mas se constitui, sobretudo, pela constante interação entre esses dois elementos. Já a noção de mobilidade populacional envolve o movimento de um grupo de pessoas pelo espaço, não se restringindo a limites políticos e sem fixação de temporalidade (HOGAN, 2005; CUNHA, 2011). Mobilidade, nesse contexto, compreende uma perspectiva ampla que abarca a migração bem como movimentos temporários, diários ou não, o que daria conta da fluidez dos movimentos dos indivíduos pelo território. 
Diversos são os exemplos de estudos sobre as inter-relações entre ambiente e mobilidade populacional, como as análises das correntes migratórias com origem no interior nordestino ainda nas décadas de 1970 e 1980 atribuídas em certa medida à seca (LAZARTE, 1986; QUEIROZ, 2013); a problematização da relação entre degradação ambiental e migração na Amazônia (SYDENSTRICKER-NETO, 2002; SAWYER, 1993); com o esgarçamento do espaço urbano (HOGAN; MARANDOLA JR.; OJIMA, 2010), tendo como uma de suas consequências o aumento de veículos pressionando a malha viária (MARTINE; OJIMA; FIORAVANTE, 2012) e deteriorando o cotidiano da vida dos moradores das cidades. Ou seja, há um vasto conjunto de processos passíveis de análise sob o enfoque das discussões sobre ambiente e mobilidade populacional.

Pretende-se neste estudo observar como as pesquisas científicas estão tratando a mobilidade populacional sob a perspectiva da sua relação com o ambiente. Para isso, foi considerada a produção científica do Grupo de Trabalho (GT) População, Espaço e Ambiente da Associação Brasileira de Estudos Populacionais $(\mathrm{ABEP})$ que tratasse da mobilidade de alguma forma. Longe de esgotar a discussão, a análise pretende trazer um panorama através da visão de um grupo que apresenta uma trajetória de reflexão sistemática desde a década de 1990, com participação em encontros nacionais e internacionais e sistematização de resultados de suas pesquisas em livros e periódicos científicos.

Este artigo se divide em duas partes, a primeira apresenta como foi realizada a seleção do material a ser analisado, enquanto a segunda analisa o conjunto de artigos, separando-os em três grupos temáticos: cidades, Amazônia e mudanças climáticas. Ao final aponta-se a síntese dos principais resultados encontrados e algumas considerações finais sobre a discussão. 
| 66 |

A mobilidade populacional...

\section{Seleção do material analisado}

Com o objetivo de investigar como as pesquisas científicas estão tratando a mobilidade populacional sob a perspectiva da sua relação com o ambiente, optou-se por tratar a produção bibliográfica do Grupo de Trabalho População, Espaço e Ambiente ${ }^{1}$ da ABEP. Os trabalhos do grupo se iniciam na década de 1990, com o objetivo de promover pesquisas sobre a interface entre população e ambiente.

A seleção de trabalhos aconteceu pela análise dos livros e periódicos organizados e relacionados ao $\mathrm{GT}^{2}$, pois se compreende que este material reuniria um conjunto de questões e debates relevantes ao grupo. Foram priorizados para a presente discussão o primeiro livro organizado pelo GT, "População, meio ambiente e desenvolvimento: verdades e contradições" publicado em 1993, e o mais recente, "População e sustentabilidade na era das mudanças ambientais globais: contribuições para uma agenda brasileira" de 2012, ambos sob coordenação de George Martine, que organiza em cada publicação artigos de diferentes autores. Desta forma foi possível comparar as mudanças ocorridas nos principais debates em que o tema da mobilidade foi abordado.

O primeiro livro tem um caráter de estabelecimento de um conjunto de temas comuns para a discussão e o início de sua fundamentação teórica para o campo de estudos da interrelação entre população e ambiente no Brasil, tratando mais da relação em aspectos gerais e buscando a construção do campo distanciado do neomalthusianismo (MARANDOLA JR.; HOGAN, 2007). O segundo livro foi direcionado ao público não acadêmico, sistematizando artigos mais curtos com discussões relevantes para a reflexão sobre a relação entre população e ambiente. Portanto, ao contrário da primeira publicação, esta apresenta textos mais sucintos com linguagem voltada a um público mais abrangente.

\footnotetext{
${ }^{1}$ Sobre a criação do GT, ver Marandola Jr. e Hogan (2007).

${ }^{2}$ Os livros relacionados são baseados na listagem oferecida pelo próprio GT, disponível no link: <http://goo.gl/yMMfHD>. Acesso em maio 2014.
} 
Além destes dois livros, realizou-se a leitura das publicações organizadas pelo GT entre os dois momentos, atentando para os trabalhos acerca de mobilidade.

\section{População, ambiente e mobilidade}

A seleção dos artigos tem como conceito central a mobilidade populacional. Como já explicitado, a mobilidade abrange a movimentação de indivíduos e, principalmente, populações pelo espaço, não se restringindo a limites políticos ou temporais (HOGAN, 2005; CUNHA, 2011). Não se trata de abandonar a conceito de migração, e sim de buscar uma perspectiva que reúna múltiplas possibilidades de movimento e de significados de movimentar-se. A proposta com tal definição é expandir o escopo de trabalhos analisados para observar a diversidade de mobilidades e sua relação com o ambiente: os pendulares, como o trajeto entre a residência e o trabalho; os de curta ou média duração, como os ribeirinhos que se destinam às cidades durante o período de cheia; e até os fluxos migratórios estabelecidos - a migração rural-urbana ou os movimentos inter-regionais (BAENINGER, 2011).

Através do material analisado, observou-se que as preocupações sobre mobilidade se desenvolveram a partir de três eixos temáticos: cidades, Amazônia e mudanças climáticas. Não são divisões estanques, uma vez que as discussões se interpõem em alguns momentos como, por exemplo, as cidades e as mudanças climáticas. Entretanto, esta subdivisão temática se mostrou útil para mapear as tendências gerais no estudo da mobilidade populacional e suas relações com o ambiente.

A investigação dessas relações se mostra relevante tendo em vista que "onde a população mora, trabalha e descansa sempre haverá impacto sobre a natureza - e vice-versa" (HOGAN, 1998: 15). Compreende-se a população em constante movimento - seja ele permanente, sazonal ou cotidiano - e em cada lugar o indivíduo impacta e é impactado de forma distinta pelo o ambiente. 
$\mid 68$ |

A mobilidade populacional...

Neste artigo, englobados no grupo temático "As cidades" estão os trabalhos analisados cujo principal foco foram os temas urbanos, com investigações que discutiram as características e dinâmicas do ambiente urbano e suas inter-relações com a mobilidade populacional. No grupo "Os migrantes e a Amazônia" sintetizam-se as análises sobre as dinâmicas que envolvem áreas rurais ou que partem de uma perspectiva regional. Por fim, o terceiro grupo compreende as discussões acerca das mudanças climáticas, tema que tem se difundido no GT População e Ambiente da ABEP. A seguir, apresentam-se algumas das principais discussões desenvolvidas no âmbito da cada um desses grupos temáticos.

\section{As cidades}

A discussão sobre as cidades permeia todo o período selecionado (1993-2012), refletindo o processo histórico de ocupação do território nacional com concentração da população nas áreas urbanas, em especial nas grandes metrópoles a partir da década de 1970. Porém, o tema transforma-se ao longo do tempo.

Entre as décadas de 1940 e 1991, a população brasileira passou por um intenso processo de urbanização. Os principais problemas ambientais, assim, viriam a se localizar principalmente no espaço urbano, com o agravante de sua constituição se dar em um país com altos índices de pobreza e com o processo de industrialização tardio (MARTINE, 1993b). Deste modo, o "problema ambiental brasileiro que afeta a maioria da população brasileira mais diretamente é um problema de áreas construídas e densamente povoadas - não de matas" (MARTINE, 1993b: 14, grifo nosso). Assim, nessas análises o espaço urbano é o principal lócus do debate, apesar de não ser o único.

Torres (2002) analisa as regiões metropolitanas do país, mostrando que o lugar onde se ocupa bem como a condição de migrante influenciam no acesso a serviços ambientais. A população nas suburban areas (p.9) - no caso as cidades periféricas 
- aumentaram em um ritmo mais acelerado que as cidades centrais das áreas metropolitanas. Além disso, as periferias apresentam indicadores de saneamento e condições ambientais piores que as cidades centrais, no geral. Deste modo, Torres (2002) defende que as políticas públicas devem se voltar para tais áreas, já que estas que recebem grande parte dos fluxos migratórios e não apresentam condições sanitárias e ambientais para suportar uma população crescente.

Um segundo aspecto importante diz respeito aos subtemas predominantemente tratados, que mudaram ao longo do tempo. Pode-se citar nessa situação a industrialização, a mobilidade pendular, a urbanização e a desigualdade (que abarca questões sobre a periferia e segregação social), a mobilidade intraurbana e, por fim, as mudanças climáticas. Estes não são constantes ao longo das duas décadas de análise, sendo predominantes em alguns períodos e arrefecendo em outros como apresentado a seguir.

A importância da industrialização está na sua capacidade de concentração demográfica por conta da massa de trabalhadores que o processo demanda, e também das consequências ambientais da sua instalação. Torres (1993) apontou a tendência do processo de industrialização de se "aglomerar num número reduzido de localidades, mesmo que em regiões diferentes" (p. 55). Além disso, as leis ambientais também influenciaram na redistribuição das indústrias, que se alocavam em espaços com leis mais flexíveis ${ }^{3}$. Assim, as concentrações populacional e industrial, aliadas aos poucos esforços de conter os problemas ambientais, criaram situações catastróficas a nível local, tal qual analisam Hogan (1993) e Costa (2000).

Hogan (1993) investiga os problemas ambientais que afetaram a população no polo petroquímico de Cubatão. "Longe de ser uma praga democrática e igualitária, que atinge todas as classes sociais da mesma maneira, a poluição é socialmente dirigida a determinados segmentos populacionais"

${ }^{3} \mathrm{O}$ trabalho de Ferreira (1993) apresenta as questões sobre a política ambiental no país e Hogan (1993) acerca da inércia política de combate à poluição. 
(HOGAN, 1993:101). Os trabalhadores residentes no município se encontravam nas camadas socioeconômicas com menor qualificação e em ocupações inferiores na hierarquia industrial, enquanto os migrantes pendulares ${ }^{4}$ ocupavam os cargos mais elevados e, consequentemente, com maiores salários em relação aos anteriores. Não morar no município com grave degradação ambiental isolou, em certa medida, os trabalhadores pendulares dos efeitos da poluição.

Costa (2000) marca um esforço em se compreender a forma como a industrialização influencia na construção do espaço urbano, mais precisamente da indústria de celulose no Vale do Aço (MG). O processo de periferização dos trabalhadores, ou seja, a fixação da população em áreas periféricas pela saída do centro ou pela vinda de migrantes de outros municípios, que traduzem a hierarquia de dentro da indústria, representou também exposição a condições ambientais desiguais. Ao contrário dos núcleos originais bem planejados, as áreas periféricas se desenvolveram de forma espontânea, com infraestrutura e serviços precários e nas proximidades da indústria.

O desenrolar do tema aconteceu pela preocupação com os estudos sobre urbanização e desigualdade social. Na verdade, o conjunto de trabalhos sobre industrialização guarda uma relação próxima com as discussões sobre o espaço. A construção social do espaço significa o enfrentamento de condições ambientais distintas, de acordo com o lugar onde se encontra na cidade ou metrópole. Reconheceu-se, com isso, o espaço como uma variável relevante para as análises de condição de vida, embora ainda exista muito para se avançar em um conceito de espaço e na construção do campo de uma demografia espacial (MARQUES, 2012).

Os trabalhos do livro de 2012 confirmaram a importância da continuidade dos temas urbanos. Costa (2012) foi responsável

\footnotetext{
${ }^{4}$ Por migração pendular compreende-se o indivíduo que mora em uma cidade e trabalha em outra, ou seja, o local de residência é diferente do de trabalho (Hogan, 1993). O movimento periódico torna-se necessário, podendo ou não ser diário. Também há mobilidade pendular para estudo.
} 
pelo primeiro capítulo da parte intitulada “Cidades, culturas e mudanças climáticas". Este funciona como uma introdução às temáticas pertinentes às cidades que são aprofundadas ao longo dessa parte. Costa (2012) traçou um histórico das metrópoles brasileiras. No passado, a formação dos aglomerados urbanos aconteceu principalmente pelo movimento do campo para a cidade e das cidades menores em direção às maiores. O presente é marcado pelos deslocamentos cotidianos pendulares: casa, trabalho, escola, saúde, comércio, entre outros e pelos deslocamentos compulsórios, com aqueles causados por políticas de remoção. E, por fim, as tendências anunciadas de expansão imobiliária e conurbação, moldadas por uma lógica capitalista de produção do espaço, que trata a cidade como mercadoria. Intrínseca a este processo está a reprodução social, pautada na desigualdade de espaço e de condições de vida.

Torres e Sydenstricker-Neto (2012) e Nakano e Cunha (2012), por sua vez, discutem o processo de periferização, relacionado às tendências futuras enunciadas por Costa (2012). A produção do espaço urbano acontece como um ciclo vicioso: conforme o investimento público melhora as estruturas de áreas periféricas até então ocupadas pela população de baixa renda, frequentemente ocasiona a elevação do custo de vida e expulsa os moradores originais para áreas ainda mais periféricas (NAKANO; CUNHA, 2012). Isso resulta em um movimento intenso de migração intrametropolitano (ou dentro da metrópole), um aspecto que tem ganhado espaço na literatura. Desta forma, a cobertura da infraestrutura urbana não acompanha a expansão da malha urbana. Com o distanciamento da ocupação dos centros, maiores a dificuldade e o tempo de espera para a chegada da infraestrutura urbana, essencial para a vida cotidiana da população.

Além disso, o espraiamento da mancha urbana ocasiona problemas em termos da mobilidade (TORRES; SYDENSTRICKERNETO, 2012). A discussão de mobilidade intraurbana, ou seja, o deslocamento nas cidades - em especial nos grandes centros focaliza as dificuldades cada vez maiores de locomoção na extensa malha urbana. Os problemas da mobilidade atualmente estariam 
em paradoxo com a própria ideia de cidade, de acesso rápido e fácil a bens e serviços. A intensificação dos deslocamentos gerou um novo conjunto de problemas e desafios às cidades, com conexões lentas e de acesso demorado. A maior necessidade de se locomover, seja para o trabalho, estudos, lazer, somado ao espraiamento do espaço urbano, resulta em um esgarçamento do espaço de vida e das relações sociais (HOGAN; MARANDOLA JR.; OJIMA, 2010).

Ao mesmo tempo, observa-se o aumento da frota de veículos no Brasil (MARTINE; OJIMA; FIORAVANTE, 2012). A participação da indústria automobilística na economia brasileira, juntamente com a dinâmica demográfica do país (concentração em grandes cidades principalmente) e a cultura do meio de transporte individual, ao invés do transporte público, explicaria o significativo aumento do número de veículos circulando na deficiente malha viária das cidades do país. Além das dificuldades de trânsito, outro problema ambiental estaria nas emissões dos gases do efeito estufa, dos veículos, provocando a degradação da qualidade do ar.

Assim, os problemas ambientais das cidades passam pelas desigualdades socioespaciais no território e o esgarçamento do espaço urbano, nos artigos mais recentes. A disponibilidade dos serviços sanitários está relacionada, em grande medida, com o quão "bem" localizado o domicílio está na malha urbana. Esta expansão sem acompanhamento de políticas públicas reforça que as desigualdades sociais também signifiquem desigualdades no acesso a serviços básicos para uma reprodução social plena. Simultaneamente, a expansão desenfreada desamparada de políticas de mobilidade coletiva provoca a obstrução das ruas da cidade.

\section{A mobilidade e a Amazônia}

A discussão sobre a Amazônia tem espaço já no primeiro livro, no ano de 1993. A Amazônia representa não apenas um recorte geográfico, mas é um símbolo da exuberância ambiental que esteve em destaque por conta dos intensos fluxos migratórios das 
décadas de 1970 e 1980. Sobre este contexto, recaíram argumentos neomalthusianos acerca da pressão populacional sobre a floresta por conta dos migrantes. Nesse contexto, um grande esforço foi feito para desmistificar cientificamente a relação superficial entre o volume populacional e a degradação dos recursos naturais.

Sawyer (1993) recorreu a uma análise sobre os fluxos migratórios dos estados da Amazônia entre 1960 e 1991, tentando compreender o crescimento da região e seu efeito no ambiente. Os fluxos migratórios foram intensos durante a década de 1970, entretanto sua intensidade diminuiu a partir de 1980. Além disso, a "fronteira agrícola" não era necessariamente rural, tendo em vista que a maioria da população da região se concentrava nas cidades. Neste sentido, a questão ambiental na Amazônia deve abranger desde o desmatamento até os problemas referente às áreas urbanas.

A preocupação neomalthusiana foi perdendo espaço ao longo do tempo, o que não evitou que grande parte da discussão sobre a Amazônia tivesse como mote desmistificar a pressão demográfica sobre os recursos naturais da floresta tropical, em especial a questão do desmatamento na região. SydenstrickerNeto (2002) discutiu o uso e cobertura da terra e os efeitos no desmatamento na Amazônia. As menores propriedades (menos de $10 \mathrm{ha})$, apesar de representarem a maioria em volume (46,7\%) em 1995-1996, eram as que ocupavam a menor área $(0,8 \%)$. Por outro lado, os estabelecimentos acima de 1.000 ha, que eram 1,9\% do total, abrangiam $62,8 \%$ de área ocupada por propriedades agrícolas. Ou seja, a presença da população é um componente importante para a análise do desmatamento, mas não deve ser o único, tendo em vista que as relações econômicas, sociais, demográficas se desenham de forma mais complexa ${ }^{5}$.

Barbieri e Guedes (2012) acrescentaram novas perspectivas a serem consideradas. A entrada das relações econômicas voltadas

\footnotetext{
${ }^{5}$ A relação entre dinâmica populacional e mudança no uso e cobertura da terra pode ser observada com mais profundidade nos artigos de Côrtes e D' Antona (2014) e VanWey, Guedes e D'Antona (2012) .
} 
para o mercado local ou global na Amazônia passa a interferir nas decisões individuais e familiares na área rural e no uso da terra. A introdução da economia formal repercutiu de forma a estruturar a economia local, refletindo no aquecimento do mercado de trabalho e na infraestrutura da região como o sistema de transporte. Além disso, a aproximação entre as áreas rurais e urbanas, não física, mas em relações sociais, potencializa a movimento de indivíduos entre esses dois espaços.

Um segundo grupo de textos se centra em estudos locais. Lima e Alencar (2000) discutem a ocupação na várzea do médio Solimões em uma reconstituição histórica do século XV até o XX. A ocupação da área se deu prioritariamente no rural. Porém, ao longo do tempo, o urbano passa a compor o cenário de ocupação com a migração pendular, causada pelas cheias do rio. As cheias inviabilizavam grande parte das atividades de pesca, agrícolas e até a habitação em algumas áreas tomadas pelas águas, e as cidades se tornaram uma alternativa para a sobrevivência nesses períodos. A imprevisibilidade da vida do rio bem como os transtornos causados criou um intenso processo de migração pendular, que por vezes culminou na migração permanente para a cidade.

Barbieri (2007a) parte de uma perspectiva da saúde, analisando a incidência da malária e a ocupação demográfica na região do norte do Mato Grosso. Em um primeiro momento, a introdução de atividades urbanas e agropecuárias significou o aumento substancial da incidência da malária. Entretanto, a manutenção da forte presença da doença se dava por conta da mobilidade da população. A circulação entre áreas de atividades de garimpo ou agropecuária, ambas realizadas próximas à floresta, com o urbano ou entre si resultava na manutenção de alta incidência da malária em ambas as áreas. Caso não houvesse uma forte interação, a incidência da doença tendia a diminuir. A mobilidade torna-se importante por aproximar locais por conta da circulação de pessoas entre estes.

Ainda sobre os estudos localizados, Vainer e Mello (2012) investigam os impactos populacionais dos grandes projetos, 
com foco em na Usina Hidrelétrica de Belo Monte ${ }^{6}$. Nesse caso, a mobilidade aconteceria de forma imposta pelos deslocamentos compulsórios, não deixando alternativas a não ser o deslocamento involuntário (VAINER; MELLO, 2012: 255). Outro movimento relevante nesse contexto é o grande fluxo de imigração visando às oportunidades geradas pelos empreendimentos. O quadro dramático causado nesse caso é o desrespeito à integridade humana, em especial às populações ribeirinhas e indígenas, em prol da pretensiosa "retórica do neodesenvolvimentismo sustentável" (VAINER; MELLO, 2012: 266).

Um terceiro grupo de trabalhos se caracteriza pela centralidade na preocupação metodológica dos estudos da Amazônia no âmbito do uso da terra, com discussões sobre metodologia multiescalar (D'ANTONA; VANWEY, 2007; BARBIERI, 2007b).

Barbieri (2007b) traz uma análise multiescalar tendo como base modelos conceituais para análise da mobilidade. A proposta é superar perspectivas disciplinares, com perspectiva econômica macro ou individualistas, para pensar uma unidade de análise que servisse a diferentes escalas, sugerindo, então, o domicílio. Com isso, se construiriam modelos analíticos para entendimento da relação da complexa causalidade entre mobilidade populacional, uso da terra e ambiente.

Por fim, cabe apontar que a aproximação da Amazônia ao Cerrado, e suas áreas de intersecção, começam a despontar na bibliografia. Primeiro o já citado artigo de Barbieri (2007a) sobre a malária no norte do Mato Grosso, sendo que uma parte do estado constitui a Amazônia Legal. O trabalho de Carmo (2012) vem justamente mostrar as atividades econômicas que estão sendo desenvolvidas na área do cerrado e de transição na atualidade, predominantemente a soja e o gado e, recentemente a cana-deaçúcar. O processo de ocupação foi marcado pelo estabelecimento de áreas urbanas por conta das atividades predominantes que não

${ }^{6}$ A usina está sendo instalada em Altamira, norte do Pará, e, em termos de potência instalada, será a terceira maior hidrelétrica do mundo. 
exigem a residência no rural. Ainda assim as atividades econômicas se voltam ao rural, o que gera um intenso deslocamento entre as áreas urbanas e as rurais para o trabalho. Ao mesmo tempo, Carmo (2012) questiona a sustentabilidade da centralidade do Centro-Oeste em tais atividades que, caso sofra com situações que dificultem sua manutenção, teria intenso respaldo nas cidades. Quer dizer, apesar de não abordar de forma explícita, a própria manutenção da população na região depende de uma economia frágil no contexto da economia internacional, o que provoca a refletir sobre possíveis movimentos migratórios.

\section{As Mudanças Climáticas}

Neste último grande grupo temático têm-se as mudanças climáticas, que surgiram no debate especialmente a partir de 2009 em livro totalmente dedicado a esta problemática - "População e mudanças climáticas: dimensões humanas das mudanças ambientais globais". A mobilidade apareceu nessa discussão principalmente como estratégia possível frente às adversidades climáticas, seja no Nordeste com o clima semiárido (QUEIROZ; BARBIERI, 2009), seja nas áreas costeiras (CARMO; SILVA, 2009; MARQUES, 2012). O que está em questão é o conhecimento do cenário que possibilite prever o risco futuro, além de seus impactos em termos sociais, demográficos, econômicos e ambientais. Marques (2012) aponta a importância da área litorânea que abriga grande parte das capitais brasileiras, como o Rio de Janeiro ou Salvador. De acordo com este autor, compreender os impactos das previsões futuras bem como os processos múltiplos dessas áreas e suas particularidades seria essencial para traçar as estratégias de enfretamento.

Entretanto, esse modo de enfrentamento se restringe a cenários futuros. Historicamente as secas periódicas do semiárido, dentre outras razões, originaram fluxos populacionais para distintas regiões do país. O que se trata neste debate seria encarar a mobilidade enquanto planejamento, reconhecendo 
o contexto local e utilizando o conhecimento sobre estudos de mudanças ambientais globais para prever seus impactos. Estes estudos vislumbraram que possivelmente os grupos mais vulneráveis apresentem maiores dificuldades para realizar a migração e sofram com os efeitos sociais e econômicos decorrentes de fenômenos climáticos (QUEIROZ; BARBIERI, 2009).

\section{Considerações sobre a mobilidade populacional e o ambiente}

Dentre os três temas mapeados, a discussão sobre "Cidades" e "Amazônia" estão presentes desde o primeiro livro organizado. Os trabalhos no início do período analisado construíram uma perspectiva crítica sobre o impacto dos fluxos migratórios para áreas mais industrializadas ou para a região da Amazônia, colocando em questão a perspectiva neomalthusiana da relação entre população e ambiente. Restringir a análise ao volume populacional é ignorar um contexto social mais complexo de, por exemplo, a desigualdade do acesso à terra ou à moradia. Não apenas o volume deve ser tratado na relação população e ambiente, mas também aspectos como o espaço de destino (urbano, rural, periferia e centro) ou as relações com as atividades econômicas exercidas neste espaço devem ser levados em conta na análise, minimizando a questão do volume.

A partir disso, cada tema desenvolveu um conjunto de preocupações próprias. A Figura 1 sintetiza os temas e subtemas de cada discussão, assim como os autores que abordaram tais questões. 
A mobilidade populacional...

TABELA 1 - A mobilidade populacional na literatura sobre população e ambiente segundo grupos temáticos e subtemas, por ano de publicação

\begin{tabular}{|c|c|c|c|c|c|c|c|}
\hline Grupo temático & 1993 & 2000 & 2002 & 2007 & 2009 & 2010 & 2012 \\
\hline \multicolumn{8}{|c|}{ As cidades } \\
\hline Industrialização & 1,2 & 3 & & & & & \\
\hline $\begin{array}{l}\text { Migração pendular } \\
\text { (entre cidades) }\end{array}$ & 2 & & & & & & \\
\hline $\begin{array}{l}\text { Urbanização e } \\
\text { desigualdade }\end{array}$ & & & 4 & & & & $5,6,7$ \\
\hline $\begin{array}{l}\text { Mobilidade pendular } \\
\text { (intraurbana) }\end{array}$ & & & & & & 8 & 9 \\
\hline \multicolumn{8}{|c|}{ A mobilidade e a Amazônia } \\
\hline Processo de ocupação & 10 & & & & & & 11 \\
\hline $\begin{array}{c}\text { Processo de ocupação } \\
\text { (local) }\end{array}$ & & 12 & & 13 & & & \\
\hline Uso da terra & & & 14 & 15,16 & & & 11 \\
\hline Grandes projetos & & & & & & & 17 \\
\hline Cerrado & & & & & & & 18 \\
\hline \multicolumn{8}{|c|}{ As Mudanças climáticas } \\
\hline $\begin{array}{c}\text { Efeitos das mudanças } \\
\text { (litoral) }\end{array}$ & & & & & 19 & & 20 \\
\hline $\begin{array}{c}\text { Efeitos das mudanças } \\
\text { (Nordeste) }\end{array}$ & & & & & 21 & & \\
\hline
\end{tabular}

Fonte: Elaboração própria.

Nota: Referências por grupos temáticos:

\section{As Cidades}

1- Torres (1993); 2- Hogan (1993); 3- Costa (2000); 4- Torres (2002); 5- Costa (2012); 6- Torres e Sydenstricker-Neto (2012); 7- Nakano e Cunha (2012); 8Hogan, Marandola Jr. e Ojima (2010); 9- Martine, Ojima e Fioravante (2012). 


\section{A mobilidade e a Amazônia}

10 - Sawyer (1993); 11 - Barbieri e Guedes (2012); 12 - Lima e Alencar (2000); 13 - Barbieri (2007a); 14 - Sydenstricker-Neto (2002); 15 - D'Antona e VanWey (2007); 16- Barbiei (2007b); 17 - Vainer e Mello (2012); 18 - Carmo (2012).

\section{As Mudanças Climáticas}

19- Carmo e Silva (2009); 20- Marques (2012); 21- Queiroz e Barbieri (2009).

As discussões sobre a degradação do ar e das águas no espaço urbano arrefeceram, não porque não se configuram mais como problemas, mas talvez pela iminência de outras questões que também são consequência das grandes aglomerações e desigualdades sociais e espaciais. Os problemas urbanos como o excesso de veículos nas vias e a expansão desordenada da mancha urbana - fruto da especulação imobiliária e, em certa medida, um descaso das políticas públicas com as cidades - invadem não somente as metrópoles, mas grande parte das cidades brasileiras.

As discussões que circundaram o recorte da Amazônia se centraram em grande medida sobre as questões rurais. A mobilidade populacional permite vislumbrar as relações estabelecidas entre espaços e população, que podem não ser contínuos, mas que se conectam e ampliam o espaço de vida das populações em uma região onde as grandes distâncias marcam o cotidiano. Aqueles que se movem, como e os porquês o fazem evidenciam dinâmicas econômicas, sociais e políticas latentes em um processo ainda arbitrário de ocupação da região. Assim parte da discussão trouxe possibilidades para refletir sobre questões como: como tratar dos processos vividos por uma região com dimensão continental e com realidades múltiplas? Como relacionar as questões micro com um contexto mais amplo?

Por fim, a área das mudanças climáticas surge mais recentemente com forte ímpeto. As preocupações estão entorno da mobilidade futura, como opção de adaptação às transformações do clima que estão por vir na forma de mobilidade racional da população. Ou em forma de mobilidade espontânea, quando não existe um planejamento adequado. 
$\mid 80$ |

A mobilidade populacional...

A mobilidade assumiu diferentes faces nas discussões sobre população e ambiente: redistribuição da população, ocupação do território, urbanização, migração, periferização, mobilidade pendular, mobilidade temporária, população flutuante e turismo. Permanentes ou temporários, aqueles que se movem o fazem sob a influência de um contexto específico, vivenciando questões ambientais, sociais, econômicas e políticas mais amplas que a própria percepção individual.

$\mathrm{Na}$ atual conjuntura, com o processo generalizado de urbanização brasileira e intensa conexão do espaço rural e urbano mesmo em economias que giram em torno do campo, torna-se imprescindível compreender a relação da população e ambiente nas metrópoles como também em cidades médias no interior do país e no litoral. Como aponta Hogan (2005), tendo em vista que vivenciamos um momento de pós-transição demográfica com o arrefecimento do crescimento populacional, o manejo consciente em termos de dinâmica demográfica será permeado pela distribuição da população pelo território tendo em conta os passivos ambientais dos espaços, como adversidades climáticas, disponibilidade de recursos ou até a contaminação. Os desafios são vários nesse sentido, em termos teóricos e metodológicos, e a literatura tem ido ao encontro deste contexto.

\section{Referências}

BAENINGER, R. Migração, migrações. Idéias - Revista do Instituto de Filosofia e Ciências Humanas da UNICAMP, v. 1, n. 2, 2011.

BARBIERI, A. F. Mobilidade populacional, meio ambiente e uso da terra em áreas de fronteira: uma abordagem multiescalar. R. bras. Est. Pop., v. 24, n. 2, p. 225-246, 2007b.

BARBIERI, A. F. População, Uso da Terra e Prevalência de Malária na Amazônia Brasileira. In. HOGAN, D. J. (Org.). Dinâmica populacional e mudança ambiental: cenários para 
o desenvolvimento brasileiro. Campinas: Núcleo de Estudos de População - Nepo/Unicamp, 2007a.

BARBIERI, A. F.; GUEDES, G. A dinâmica demográfica e seus impactos ambientais na Amazônia: atualizações necessárias para uma política regional. In. MARTINE, G. (Ed.). População e sustentabilidade na era das mudanças ambientais globais: contribuições para uma agenda brasileira. Belo Horizonte: ABEP, 2012.

CARMO, R. L. Cerrado: água, fogo e sustentabilidade. In: MARTINE, G. (Ed.). População e sustentabilidade na era das mudanças ambientais globais: contribuições para uma agenda brasileira. Belo Horizonte: ABEP, 2012.

CARMO, R. L.; SILVA, C. A. M. População em zonas costeiras e mudanças climáticas: redistribuição populacional e riscos. In: HOGAN, D. J.; MARANDOLA JR., E. (Eds.). População e mudanças climáticas: dimensões humanas das mudanças ambientais globais. Campinas; Brasília: Núcleo de Estudos de População - Nepo/Unicamp; UNFPA, 2009.

CÔRTES, J. C.; D'ANTONA, A. O. Dinâmicas no uso e cobertura da terra: perspectivas e desafios da Demografia. Revista R. bras. Est. Pop., v. 31, 2014.

COSTA, H. S. M. Indústria e produção do espaço e custos socioambientais: reflexões a partir do exemplo do Vale do Aço, Minas Gerais. In. COSTA, H. S. M.; TORRES, H. (Orgs.). População e meio ambiente: debates e desafios. São Paulo: Editora SENAC São Paulo, 2000.

COSTA, H. S. M. Planejamento e ambiente em regiões metropolitanas. In. MARTINE, G. (Ed.). População $e$ sustentabilidade na era das mudanças ambientais globais: contribuições para uma agenda brasileira. Belo Horizonte: ABEP, 2012.

CUNHA, J. M. P. Mobilidade espacial da população: desafios teóricos e metodológicos para o seu estudo. In. CUNHA, J. 
M. P. (Org.). Mobilidade espacial da população: desafios teóricos e metodológicos para o seu estudo. Campinas: Núcleo de Estudos de População - Nepo/Unicamp, 2011.

D’ANTONA, A O.; CAK, A. D.; VANWEY, L. K. Efeitos da escala da análise em estudos de mudança da cobertura da terra entre Santarém e Altamira, no Pará, Brasil. In. HOGAN, D. J. (Org.). Dinâmica populacional e mudança ambiental: cenários para o desenvolvimento brasileiro. Campinas: Núcleo de Estudos de População - Nepo/Unicamp, 2007.

D'ANTONA, A. O.; VANWEY, L. K. Estratégia para amostragem da população e da paisagem em pesquisas sobre uso e cobertura da terra. R. bras. Est. Pop., v. 24, n. 2, p. 263-275. 2007.

FERREIRA, L. C. A política ambiental no Brasil. In. MARTINE, G. (Org.). População, meio ambiente e desenvolvimento: verdades e contradições. Campinas: Editora da UNICAMP, 1993.

FERREIRA, L. C. Mobilidade populacional e meio ambiente. R. bras. Est. Pop., v. 15, n. 2, p. 83-92, 1998.

FERREIRA, L. C. Mobilidade populacional, sustentabilidade ambiental e vulnerabilidade social. R. bras. Est. Pop., São Paulo, v. 22, n. 2, p. 323-338, 2005.

FERREIRA, L. C. População, pobreza e poluição em Cubatão, São Paulo. In. MARTINE, G. (Org.). População, meio ambiente e desenvolvimento: verdades e contradições. Campinas: Editora da UNICAMP, 1993.

HOGAN, D.; MARANDOLA JR., E.; OJIMA, R. Aglomerações urbanas e mobilidade. In. HOGAN, D.; MARANDOLA JR., E.; OJIMA, R. (Orgs.). População e Ambiente: desafios à sustentabilidade. Série Sustentabilidade. São Paulo: Blucher, 2010.

LAZARTE, R. Tendências recentes de crescimento e distribuição espacial da população brasileira. Anais... V Encontro Nacional de Estudos Populacionais. Águas de São Pedro-SP, 1986. 
LEFF, E. Aventuras da epistemologia ambiental: da articulação das ciências ao diálogo de saberes. São Paulo: Cortez, 2012.

LIMA, D. M.; ALENCAR, E. F. Histórico da ocupação humana e mobilidade geográfica de assentamentos na várzea do médio Solimões. In. COSTA, H. S. M.; TORRES, H. (Orgs.). População e meio ambiente: debates e desafios. São Paulo: Editora SENAC São Paulo, 2000.

MARANDOLA JR., E.;HOGAN, D. J. Em direção a uma demografia ambiental? Avaliação e tendências dos estudos de População e Ambiente no Brasil. R. bras. Est. Pop., v. 24, n. 2, p. 191-223, 2007.

MARQUES, C. Desafios teóricos e tendências recentes na demografia espacial e ambiental brasileira. In. Anais... XVIII Encontro Nacional de Estudos Populacionais, Águas de Lindóia, 2012.

MARTINE, G. A demografia na questão ecológica: falácias e dilemas reais. In. MARTINE (Org.). População, meio ambiente e desenvolvimento: verdades e contradições. Campinas: Editora da UNICAMP, 1993a.

MARTINE, G. População, meio ambiente e desenvolvimento: o cenário global e nacional. In. MARTINE (Org.). População, meio ambiente e desenvolvimento: verdades e contradições. Campinas: Editora da UNICAMP, 1993b.

MARTINE, G.; OJIMA, R.; FIORAVANTE, E. F. Transporte individual, dinâmica demográfica e meio ambiente. In. MARTINE, G. (Ed.). População e sustentabilidade na era das mudanças ambientais globais: contribuições para uma agenda brasileira. Belo Horizonte: ABEP, 2012.

NAKANO, K.; CUNHA, J. M. P. A Rio+20 e os desafios da crise urbana. In. MARTINE, G. (Ed.). População e sustentabilidade na era das mudanças ambientais globais: contribuições para uma agenda brasileira. Belo Horizonte: ABEP, 2012. 
QUEIROZ, B. L.; BARBIERI, A. Os potenciais efeitos das mudanças climáticas sobre as condições de vida e a dinâmica populacional no Nordeste Brasileiro. In. HOGAN, D. J.; MARANDOLA JR., E. (Orgs.). População e mudanças climáticas: dimensões humanas das mudanças ambientais globais. Campinas; Brasília: Núcleo de Estudos de População - Nepo/ Unicamp; UNFPA, 2009.

QUEIROZ, S. N. Migrações, retorno e seletividade no mercado de trabalho cearense. Tese de Doutorado. Universidade Estadual de Campinas (UNICAMP). Campinas, SP. 2013. Disponível em: <http://goo.gl/Ank1dx>. Acesso em out. 2014.

SAWYER, D. População e meio ambiente na Amazônia brasileira. In. MARTINE, G. (Org.). População, meio ambiente e desenvolvimento: verdades e contradições. Campinas: Editora da UNICAMP, 1993.

SYDENSTRICKER-NETO, J. Population and Environment in Amazonia: from just the numbers to what really counts. In. HOGAN, D. J.; BERQUÓ, E.; COSTA, H. S. M. (Eds.). Population and environment in Brazil: Rio+10. Campinas: CNPD, Abep, Nepo, 2002.

TORRES, H. G. Indústrias sujas e intensivas em recursos naturais: importância crescente no cenário industrial brasileiro. In. MARTINE, G. (Org.). População, meio ambientee desenvolvimento: verdades e contradições. Campinas: Editora da UNICAMP, 1993.

TORRES, H. G. Migration and Environment: a view from Brazilian Metropolitan Areas. In. HOGAN, D. J.; BERQUÓ, E.; COSTA, H. S. M. (Orgs.). Population and environment in Brazil: Rio+10. Campinas: CNPD, Abep, Nepo, 2002.

TORRES, H. G.; SYDENSTRICKER-NETO, J. Por uma periferia sustentável. In. MARTINE, G. (Ed.). População e sustentabilidade na era das mudanças ambientais globais: contribuições para uma agenda brasileira. Belo Horizonte: ABEP, 2012. 
VAINER, C.; MELLO, C. C. A. Grandes projetos, deslocamentos compulsórios e meio ambiente: o caso de Belo Monte. In. MARTINE, G. (Ed.). População e sustentabilidade na era das mudanças ambientais globais: contribuições para uma agenda brasileira. Belo Horizonte: ABEP, 2012.

VANWEY, L. K.; GUEDES, G. R.; D'ANTONA, A. O. Out-migration and land-use change in agricultural frontiers: insights from Altamira settlement project. Population and Environment, v. 34, 2012. 